\title{
RAPID DIAGNOSIS OF DENGUE VIREMIA BY REVERSE TRANSCRIPTASE-POLYMERASE CHAIN REACTION USING 3'-NONCODING REGION UNIVERSAL PRIMERS
}

\author{
T. MIRAWATI SUDIRO, HIROAKI ISHIKO, SHARONE GREEN, DAVID W. VAUGHN, ANANDA NISALAK, \\ SIRIPEN KALAYANAROOJ, ALAN L. ROTHMAN, BOONYOS RAENGSAKULRACH, \\ JURAND JANUS, ICHIRO KURANE, AND FRANCIS A. ENNIS \\ Division of Infectious Diseases and Immunology, University of Massachusetts Medical School, Worcester, Massachusetts; \\ Department of Virology, U.S. Army Medical Component, Armed Forces Research Institute of Medical Sciences, \\ Bangkok, Thailand; Department of Infectious Disease, Bangkok Children's Hospital, Bangkok, Thailand
}

\begin{abstract}
A reverse transcriptase-polymerase chain reaction (RT-PCR) method was developed as a rapid diagnostic test of dengue viremia. To detect dengue viruses in serum or plasma specimens, a pair of universal primers was designed for use in the RT-PCR. Using these primers, the $3^{\prime}$-noncoding region of dengue virus types $1,2,3$, and 4 could be amplified, but not those of other flaviviruses, such as West Nile virus, Japanese encephalitis virus, and yellow fever virus, or the alphavirus Sindbis virus. The sensitivity of the RT-PCR assay was similar to that of a quantitative fluorescent focus assay of dengue viruses in cell culture. Combining a silica method for RNA isolation and RT-PCR dengue virus could be detected in a 6-hr assay. In a preliminary study using this method, we detected dengue virus in 38 of 39 plasma specimens from which dengue virus had been isolated by mosquito inoculation. We then applied this method for detecting dengue viremia to 117 plasma samples from 62 children with acute febrile illnesses in a dengue-endemic area. We detected dengue viremia in 19 of 20 samples obtained on the day of presentation, which had been confirmed as acute dengue infection by mosquito inoculation and antibody responses. The overall sensitivity of this method was $91.4 \%(32$ of $35 ; 95 \%$ confidence interval $[\mathrm{CI}]=82.2-100 \%)$. The results from testing plasma samples from febrile nondengue patients showed a specificity of $95.4 \%(42$ of $44 ; 95 \% \mathrm{CI}=$ 89.3-100\%).
\end{abstract}

Dengue virus infections can cause two forms of disease; dengue fever and dengue hemorrhagic fever. Dengue fever is a self-limited, febrile disease while dengue hemorrhagic fever can lead to life-threatening complications. Currently, the laboratory diagnosis of dengue infection depends upon isolation of dengue virus using mosquito cell cultures ${ }^{1}$ or inoculation of mosquitoes; ${ }^{2}$ or detection of anti-dengue antibody by IgM or IgG ELISA ${ }^{3}$ and/or hemagglutination inhibition assays. ${ }^{4}$ Virus isolation, which is specific and relatively sensitive early in infection, is tedious and time-consuming. Serologic tests, while simple to perform, generally require paired serum samples. ${ }^{3.5}$

The polymerase chain reaction (PCR) has the potential for sensitive, specific, and rapid detection of minute quantities of certain genetic material in clinical specimens, thus providing an attractive approach for the rapid identification of dengue infection. Several methods of reverse transcriptase (RT)-PCR using different pairs of primers for dengue viruses and different approaches for the detection of amplification products have been previously reported..$^{5-14}$ However, most of the published methods require more than $24 \mathrm{hr}$ for analysis. Rapid RT-PCR methods for detection of dengue viremia have been reported, ${ }^{5.7 .10 .11 .13}$ but they have not been validated for detecting all four dengue serotypes in clinical specimens.

In this report we describe a rapid RT-PCR procedure using primers that amplify the $3^{\prime}$-noncoding region of dengue virus types $1,2,3$, and 4, but not those of other flaviviruses, such as West Nile virus, Japanese encephalitis virus, and yellow fever virus, or the alphavirus Sindbis virus. Combining a silica method for RNA isolation and the RT-PCR, we could detect dengue virus in serum or plasma within $6 \mathrm{hr}$. The data presented in this paper demonstrate that this assay is sufficiently rapid and sensitive to allow early diagnosis of dengue virus infections.

\section{MATERIALS AND METHODS}

Plasma samples. Blood samples were obtained from children enrolled in a prospective study of dengue infections at the Children's Hospital, Bangkok, Thailand, and the Kamphaeng Phet Provincial Hospital, Kamphaeng Phet, Thailand, in 1994 (Kalayanarooj $S$ and others, unpublished data). Children with fever of $72 \mathrm{hr}$ or less in duration and facial flushing without obvious cause were eligible to participate in this study. Written consent was obtained from the subject's parents or guardians. The study protocol was approved by Institutional Review Boards established by the Ministry of Public Health, Thailand, the Surgeon Generals's Office of the Department of the Army, and the University of Massachusetts Medical Center. Blood was drawn daily until one day after defervescence or up to five days, and then at convalescence (8-10 days after enrollment). Blood was collected into EDTA-containing tubes; plasma was separated and stored at $-70^{\circ} \mathrm{C}$ until the RT-PCR was performed. Each specimen collected had dengue IgM and IgG ELISA and hemagglutination inhibition assays performed. Dengue virus isolation was attempted by mosquito inoculation ${ }^{2}$ for the first three consecutive days or until virus isolation was negative on subsequent days tested (Vaughn DW and others, unpublished data). A child was diagnosed as having acute dengue infection when the serologic test results were positive, and/or dengue virus could be isolated. Control specimens used in this study were from children with febrile illness but no evidence of acute dengue infection by serologic tests with appropriately timed specimens and when mosquito inoculation test results were negative for dengue virus in their plasma.

Extraction of RNA. The RNA was extracted from human serum spiked with dengue virus or human plasma from febrile patients by a modification of the silica method that was first described by Boom and others, ${ }^{15}$ and later applied to 
$\mathbf{A}$

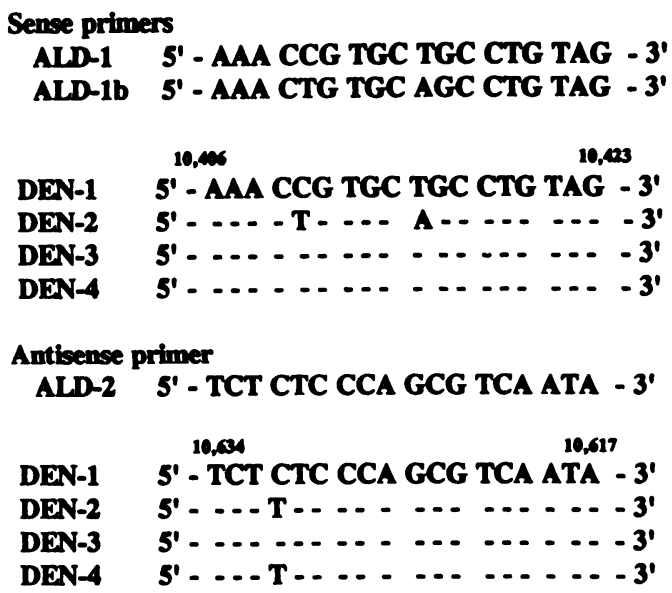

B

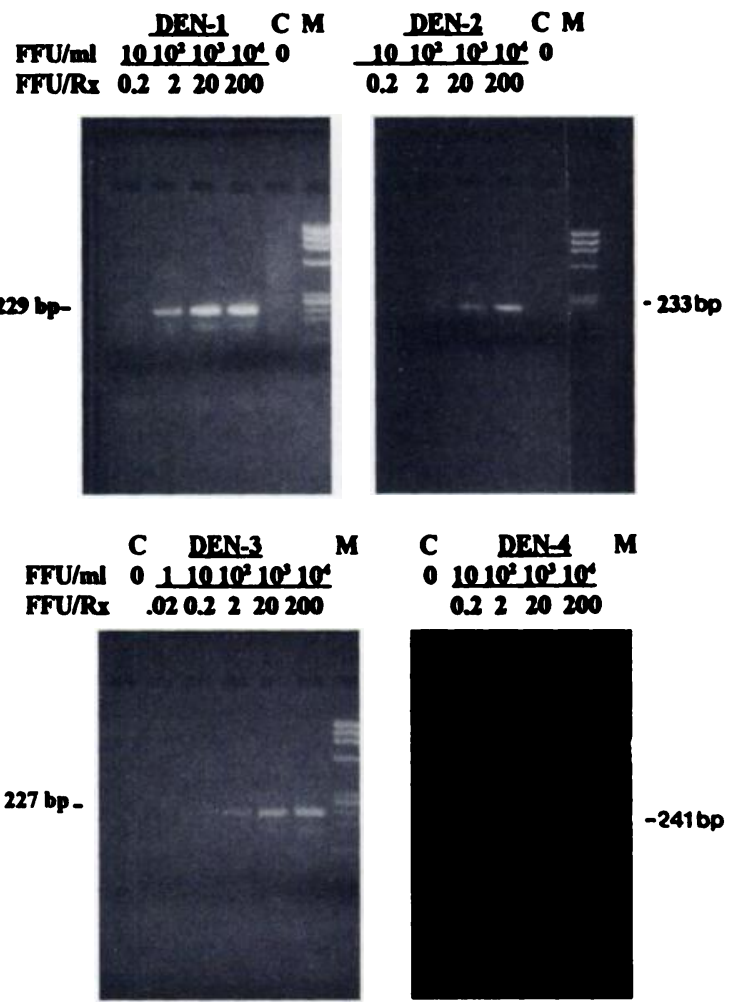

FigURE 1. A, sequence alignment of primers ALD-1, ALD-1b, and ALD-2 with dengue (DEN) virus conserved regions. The nucleotides are numbered according to the dengue-1 genome described by $\mathrm{Fu}$ and others. ${ }^{16} \mathrm{~B}$, ethidium bromide-stained agarose gels for analyzing the sensitivity of the reverse transcriptase-polymerase chain reaction (RT-PCR) for dengue virus types 1 to 4 as described in the Materials and Methods. Lane C, normal human serum used as a negative control; lane M, molecular weight marker ( $\phi$ X174 replicative form DNA digested with Hae III). The location of the expected PCR products are shown (229 basepairs [bp], $233 \mathrm{bp}, 227$ bp, and 241 bp for dengue virus type $1,2,3$, and 4, respectively). FFU = fluorescent focus units; FFU/Rx = fluorescent focus unit per reaction.

isolation of dengue virus RNA. ${ }^{5.7 .13}$ Briefly, $20 \mu$ l of sample was vortexed for $5 \mathrm{sec}$ with $180 \mu \mathrm{l}$ of lysing buffer $(4 \mathrm{M}$ guanidine isothiocyanate, $40 \mathrm{mM}$ Tris- $\mathrm{HCl} \mathrm{pH} 6.4,17 \mathrm{mM}$ EDTA, pH 8.0, $1 \%$ Triton $X-100)$ and $8 \mu$ l of acid-treated size fractionated silica particles (Sigma Chemicals, St. Louis, MO), then allowed to stand at room temperature for $10 \mathrm{~min}$, mixed again, and pelleted by centrifugation at 13,000 $\times g$ for $15 \mathrm{sec}$. The silica pellet was washed twice in $200 \mu \mathrm{l}$ of washing buffer (50\% ethanol, $10 \mathrm{mM}$ Tris- $\mathrm{HCl}, \mathrm{pH} \mathrm{7.4,1}$ mM EDTA, and $50 \mathrm{mM} \mathrm{NaCl}$ ), and finally rinsed in $100 \mu \mathrm{l}$ of diethyl pyrocarbonate-treated water. The pellet was resuspended in $15 \mu \mathrm{l}$ of water containing $2.5 \mathrm{U}$ of RNase inhibitor (Pharmacia, Piscataway, $\mathrm{NJ}$ ) and incubated at $56^{\circ} \mathrm{C}$ for $7 \mathrm{~min}$. After centrifugation at $13,000 \times g$ for $2 \mathrm{~min}, 14$ $\mu l$ of the RNA sample was collected.

Primers. We analyzed the sequence data on dengue viruses in the Genbank database (National Center for Biotechnology Information, Bethesda, MD). We chose to analyze the noncoding region that is thought to function in regulation of virus replication and that we expected to be well conserved among dengue viruses. We compared the sequences of dengue virus type 1 Singapore S275/90 strain ${ }^{16}$ (Genbank accession M87512), dengue virus type 2 New Guinea C strain $^{17}$ (M29095 M19727), dengue virus type 2 Jamaica strain $^{18}$ (M20558), dengue virus type $2 \mathrm{~S} 1$ vaccine strain $^{19}$ (M19197), dengue virus type 3 H87 strain $^{20}$ (M93130), dengue virus type 4 Caribbean 814669 strain $^{21}$ (M14931
M17255), and the related viruses Japanese encephalitis virus $^{22}$ (M18370, MS5506, D90195), yellow fever virus ${ }^{23}$ (K02749), and Kunjin virus ${ }^{24}$ (D00246). We found a region corresponding to nucleotides 10,406 to 10,423 of dengue-1 that is highly conserved in all four serotypes of dengue virus. Within this region, only two base changes in dengue- 2 were found. In the other flaviviruses checked, with maximal alignment, a difference of at least five bases was found. For the sense primer we chose a mixture of the sequence homologous to dengue 1, 3, and 4 (ALD-1: 5'-AAA CCG TGC TGC CTG TAG-3') and the sequence homologous to dengue-2 (ALD-1b: 5'-AAA CTG TGC AGC CTG TAG-3'). For the antisense primer, we selected an oligonucleotide that is complementary to nucleotides 10,617 to 10,634 of dengue-1 (ALD-2: 5'-TCT CTC CCA GCG TCA ATA-3'). This sequence is also conserved in dengue-3. In dengue- 2 and dengue-4, there is a single base difference (Figure $1 \mathrm{~A}$ ). In Japanese encephalitis virus and yellow fever virus, there are four and three base mismatches, respectively. Despite the highly conserved nature of our primers, the regions between the primers are quite variable. The sequence identity of the PCR products among the four serotypes of dengue virus ranges between $77 \%$ and $90 \%$. The expected sizes of the PCR products are 229 basepairs (bp), 233 bp, 227 bp, and $241 \mathrm{bp}$ for dengue virus types $1,2,3$, and 4 , respectively.

Reverse transcriptase-polymerase chain reaction. The method we used consists of reverse transcription using the 
downstream primer ALD-2, heat inactivation of the reverse transcriptase, and PCR incorporating the upstream primers ALD-1 and ALD-1b. Fourteen microliters of isolated RNA was added to $6 \mu$ l of RT mixture solution containing $50 \mathrm{mM}$ $\mathrm{KCl}, 10 \mathrm{mM}$ Tris- $\mathrm{HCl}\left(\mathrm{pH} 9.0\right.$ at $25^{\circ} \mathrm{C}$ ), $0.1 \%$ Triton $\mathrm{X}-100$, $1.0 \mathrm{mM} \mathrm{MgCl}_{2}, 25 \mathrm{pmol}$ of downstream primer ALD-2, 0.2 $\mathrm{mM}$ of each dNTP, $2.0 \mathrm{U}$ of avian myeloblastosis virus (AMV) reverse transcriptase (Promega, Madison, WI), and 4.0 U of RNase inhibitor (Pharmacia). Reverse transcription was carried out at $42^{\circ} \mathrm{C}$ for $30 \mathrm{~min}$, followed by inactivation of the reverse transcriptase at $95^{\circ} \mathrm{C}$ for $5 \mathrm{~min}$. Thirty microliters of the PCR mixture was then added to the reaction mixture. The PCR mixture contains $50 \mathrm{mM} \mathrm{KCl}, 10 \mathrm{mM}$ Tris- $\mathrm{HCl}\left(\mathrm{pH} 9.0\right.$ at $\left.25^{\circ} \mathrm{C}\right), 0.1 \%$ Triton X-100, $1.0 \mathrm{mM}$ $\mathrm{MgCl}_{2}, 25$ pmol of each upstream primer ALD-1 and ALD1b, $0.2 \mathrm{mM}$ of each dNTP, and 1.25 U of Tth DNA polymerase (Promega). The reaction was carried out at $92^{\circ} \mathrm{C}$ for $1 \mathrm{~min}, 53^{\circ} \mathrm{C}$ for $1 \mathrm{~min}$, and $72^{\circ} \mathrm{C}$ for $1 \mathrm{~min}$ for 10 cycles, and continued at $92^{\circ} \mathrm{C}$ for $30 \mathrm{sec}, 55^{\circ} \mathrm{C}$ for $30 \mathrm{sec}$, and $72^{\circ} \mathrm{C}$ for $30 \mathrm{sec}$ for 30 cycles, followed by incubation at $72^{\circ} \mathrm{C}$ for $5 \mathrm{~min}$. Fifteen microliters of sample was subjected to $2.2 \%$ agarose gel electrophoresis and the gel was then stained with ethidium bromide.

Viruses. To optimize the RT-PCR technique and to analyze its sensitivity, we used reference virus strains: dengue virus type 1 Hawaii strain, dengue virus type 2 New Guinea C strain, dengue virus type 3 CH53489 strain, and dengue virus type 4814669 strain.

Fluorescent focus assay. Virus stocks were titered by fluorescent focus assay in CV-1 cells. ${ }^{25}$ Briefly, cells were infected with serially diluted virus in eight-chamber slides. After incubation for $20 \mathrm{hr}$ at $37^{\circ} \mathrm{C}$, slides were fixed and stained using an indirect fluorescent antibody technique using mouse anti-dengue hyperimmune ascitic fluid and fluorescein isothiocyanate (FITC)-conjugated sheep anti-mouse IgG, and infected cells were counted. Our unpublished data showed that the sensitivity of this method is comparable to a plaque assay in CV-1 cells.

Mosquito inoculation assay. Virus culture was performed by the method described by Rosen and Gubler. ${ }^{2}$ Briefly, undiluted plasma was inoculated into adult Toxorhynchites splendens $(0.34 \mu l$ per mosquito, 20 mosquitoes per specimen). Mosquitoes were incubated at $30^{\circ} \mathrm{C}$ for $12-14$ days. Infected mosquitoes were detected by fluorescent antibody (FA) staining of head squashes using polyvalent anti-dengue mouse ascitic fluid and anti-mouse IgG-FITC. All mosquito bodies from specimens that yielded at least one FA-positive head were triturated in RPMI 1640 medium plus $10 \%$ fetal calf serum; triturates were passaged one or more times in $25-\mathrm{cm}^{2}$ tissue culture flasks of $\mathrm{C} 6 / 36$ cells for seven days. Culture supernatants were assayed with virus-specific monoclonal antibodies [flavivirus group (4G2), dengue complex (2H2), dengue-1 (1F1), dengue-2 (3H5), dengue-3 (10C10), dengue-4 (1H10), Japanese encephalitis virus (J93)] in an antigen-capture ELISA. ${ }^{26}$

\section{RESULTS}

Sensitivity and specificity of the RT-PCR. The sensitivity of the RT-PCR was determined by comparison with the immunofluorescent focus assay. The RT-PCR was applied to normal human serum (human AB serum; Advanced Biotechnologies Inc., Columbia, MA) spiked with 10-fold serial dilutions of reference virus stocks. The RNA was isolated from each dilution and was subjected to RT-PCR as described in the Materials and Methods. Water used to elute the RNA or human $A B$ serum was used as a negative control. As seen in Figure 1B, the sensitivity of the RT-PCR in detecting virus RNA in human serum is at least 2 fluorescent focus units (FFU)/20- $\mu$ l sample for dengue-1, 3, and, 4 viruses, and $20 \mathrm{FFU} / 20-\mu \mathrm{l}$ sample for dengue- 2 virus. Other than the bands of expected size, there was a minor faint band that migrated faster than the major band in samples containing dengue-1, dengue- 3 , and dengue- 4 . This minor band decreased in intensity in parallel to the intensity of the major band in serial dilutions of virus as well as by increasing the annealing temperature, and was not present in negative serum controls. We speculate that this band might result from the secondary structure of the 3 '-noncoding region products.

This method also gave positive results with other laboratory strains of dengue viruses tested, including dengue virus type-1 Mochizuki strain, dengue virus type-2 strains Thai257 and M11355, dengue virus type 3 strains Sri Lanka-904 and Sri Lanka-969, and dengue virus type 4 strains H241 and Thai-286. Results were negative for West Nile virus, yellow fever virus, Japanese encephalitis virus, and Sindbis virus.

Preliminary study of plasma specimens from children with acute dengue infection. In a preliminary study to confirm whether our results with serum spiked with dengue virus also applied to clinical samples, we applied our method to 39 plasma samples from children with dengue fever or dengue hemorrhagic fever. Dengue virus had previously been isolated from these samples by mosquito inoculation. We tested six samples containing dengue-1, 10 samples with dengue-2, six samples with dengue-3, and 16 samples with dengue-4. All the samples had been obtained on the day of clinic presentation, no more than $72 \mathrm{hr}$ after the onset of fever, and from zero to five days before defervescence. Results of PCR analysis are shown in Table 1 by day relative to defervescence. Thirty eight of the 39 samples were positive by RT-PCR. The one negative specimen was obtained from a dengue-2-virus infected patient on the last day of fever. Two samples from healthy persons and one sample from a patient with hepatitis $\mathrm{C}$ gave negative results.

Comparison of RT-PCR and mosquito inoculation for detection of viremia. To further study the sensitivity and specificity of this RT-PCR method in comparison with the mosquito inoculation method, we tested plasma specimens from 20 subjects known to have dengue viremia, comprising five subjects infected with each of the four serotypes. For each subject, we studied the plasma sample obtained at enrollment (study day 1 ), the last daily plasma sample that yielded dengue virus by mosquito inoculation (last mosquito inoculation positive), the plasma sample from the next daily bleed (first mosquito inoculation negative), and the convalescent sample (follow-up). In most cases mosquito inoculation was not performed on follow-up plasma specimens because a previous blood specimen was negative for viremia and we assumed that later samples would have been negative if tested. We tested a total of 73 samples from these 20 patients; in some cases the last mosquito inoculation positive 
TABLE 1

Comparison of reverse transcriptase-polymerase chain reaction with mosquito inoculation for dengue virus detection in plasma specimens (preliminary study)

\begin{tabular}{ccccccccc}
\hline & & \multicolumn{5}{c}{ Day that samples were obtained relative to defervescence* } \\
\cline { 3 - 9 } Dengue serotype & Total & -5 & -4 & -3 & -2 & -1 & 0 & Unknownt \\
\hline Dengue-1 & $6 / 6$ & - & $2 / 2$ & $1 / 1$ & $2 / 2$ & $1 / 1$ & - \\
Dengue-2 & $10 / 11$ & $1 / 1$ & $2 / 2$ & $3 / 3$ & $2 / 2$ & $2 / 2$ & $0 / 1$ \\
Dengue-3 & $6 / 6$ & - & - & $2 / 2$ & $2 / 2$ & $1 / 1$ & - & $1 / 1$ \\
Dengue-4 & $16 / 16$ & - & - & $4 / 4$ & $8 / 8$ & $4 / 4$ & - & - \\
Total & $38 / 39$ & $1 / 1$ & $4 / 4$ & $10 / 10$ & $14 / 14$ & $8 / 8$ & $0 / 1$ & $1 / 1$ \\
\hline
\end{tabular}

* The day when the body temperature decreased and remained below $38^{\circ} \mathrm{C}$ is defined as day zero.

+ Subject withdrawn from the study before defervescence.

was the same as the study day 1 sample or no blood sample was obtained on the day after the last mosquito inoculation positive sample. As a control group, we selected at random plasma samples obtained at enrollment from 44 study subjects who had no serologic evidence of dengue infection and whose blood samples were negative for dengue viremia by mosquito inoculation. Coded specimens were tested by RT-PCR.

Of the 73 samples obtained from patients with dengue infection, 35 samples were positive by mosquito inoculation, while RT-PCR detected dengue viremia in 38 samples. Thirty-two of the RT-PCR-positive samples were also positive by mosquito inoculation, and six samples were mosquito inoculation negative or not done. Three of 35 samples positive by mosquito inoculation were negative by RT-PCR. Among 44 samples from the febrile nondengue control group, two samples were positive by RT-PCR (Table 2).

Tables 3 and 4 show RT-PCR results for samples from patients with dengue viremia with reference to the time of sample collection. Of 20 samples obtained on the day of presentation, we detected dengue virus in 19 samples by RT-PCR. The one negative sample was obtained from a dengue-2-infected patient two days before defervescence. Of the 20 samples obtained on the last day that yielded dengue virus by mosquito inoculation, from three days before to one day after defervescence, we detected dengue viremia by RT-PCR in 17 samples, but failed to detect dengue RNA in one sample each of dengue- 2 , dengue- 3 , and dengue- 4 . Of the 18 first mosquito inoculation-negative samples, obtained between two days before and one day after defervescence, we detected dengue virus in two samples that were positive in mosquitoes for dengue- 3 and in one sample positive for

TABLE 2

Comparison of reverse transcriptase-polymerase chain reaction (RTPCR) with mosquito inoculation for detection of dengue viremia during acute febrile illness

\begin{tabular}{|c|c|c|c|}
\hline & \multicolumn{2}{|c|}{ Dengue* } & \multirow{2}{*}{$\begin{array}{c}\text { Nondenguet } \\
\begin{array}{c}\text { Virus } \\
\text { isolation } \\
\text { negative }\end{array}\end{array}$} \\
\hline & $\begin{array}{l}\text { Virus } \\
\text { isolation } \\
\text { positive }\end{array}$ & $\begin{array}{c}\text { Virus } \\
\text { isolation } \\
\text { negative }\end{array}$ & \\
\hline RT-PCR positive & 32 & $6 \ddagger$ & $2 \S$ \\
\hline RT-PCR negative & 3 & 32 & 42 \\
\hline Total & 35 & 38 & 44 \\
\hline
\end{tabular}

* Acute febrile dengue virus infection confirmed by mosquito inoculation and serologic tests.

+ Acute febrile illness without evidence of acute dengue infection by mosquito inoculation and complete serologic testing.

¥ Five of these showed weak bands and were negative on repeat testing. $\S$ Both showed weak bands and were negative on repeat testing. dengue-4. Of 19 follow-up samples we detected dengue viremia by $R T-P C R$ in one sample from a dengue-1-infected patient obtained four days after defervescence, and in two dengue- 2 samples that were obtained five and seven days after defervescence. Results from these samples showed weak bands. Mosquito inoculation assays had not been performed on these specimens.

We repeated RT-PCR on samples that gave discrepant results between RT-PCR and mosquito inoculation. Two follow-up samples (both dengue-2), two first mosquito inoculation-negative samples (both dengue-3), one last mosquito inoculation-positive sample, and two samples from the control group, which were positive by RT-PCR on the first test, were negative on repeat testing. One dengue-3 sample that was negative in the first RT-PCR and positive for mosquito inoculation gave a positive result on the second test.

\section{DISCUSSION}

We describe an alternative method for a sensitive, rapid, simple and economical RT-PCR procedure for the diagnosis of dengue virus infection. There are several reports describing RT-PCR for the detection of dengue virus using different approaches for the amplification of viral RNA and the detection of the PCR product. The objectives of several of these reports were to detect and determine the serotype of virus strains that had been isolated in mosquitoes or tissue culture. For this purpose, RT-PCR followed by hybridization $^{8.12}$ or nested PCR ${ }^{9}$ gave good results. Although the sensitivity was good, these procedures still required considerable time and labor for use in patient management. Morita and others ${ }^{10.11}$ proposed a rapid and simple method using NP-40 and type-specific primers in which RNA isolation,

TABLE 3

Reverse transcriptase-polymerase chain reaction (RT-PCR) positivity of plasma from patients infected with dengue virus

\begin{tabular}{ccccc}
\hline & \multicolumn{4}{c}{ Sample (PCR +/no. tested) } \\
\cline { 2 - 5 } Virus & Day I & Last MI+* & Ist MI- & Follow-up \\
\hline Dengue-1 & $5 / 5$ & $4 / 5$ & $0 / 5$ & $1 / 5$ \\
Dengue-2 & $4 / 5$ & $4 / 5 \ddagger$ & $0 / 4$ & $2 / 5$ \\
Dengue-3 & $5 / 5$ & $4 / 5 \ddagger$ & $2 / 4$ & $0 / 4$ \\
Dengue-4 & $5 / 5$ & $5 / 5 \ddagger$ & $1 / 5$ & $0 / 5$ \\
Total & $19 / 20$ & $17 / 20$ & $3 / 18$ & $3 / 19$ \\
\hline
\end{tabular}

* The last daily plasma sample that yielded dengue virus by mosquito inoculation (MI) the first daily plasma sample that was negative for dengue virus by mosquito inocu-

$\ddagger$ One of these samples was a first day sample. 
TABLE 4

Detection of dengue virus by mosquito inoculation (MI) and reverse transcriptase-polymerase chain reaction (RT-PCR) during the course of illness*

\begin{tabular}{|c|c|c|c|c|c|c|c|c|c|c|}
\hline \multirow[b]{2}{*}{ Fever day ${ }^{\dagger}$} & \multicolumn{2}{|c|}{ Total } & \multicolumn{2}{|c|}{ Dengue-1 } & \multicolumn{2}{|c|}{ Dengue-2 } & \multicolumn{2}{|c|}{ Dengue-3 } & \multicolumn{2}{|c|}{ Dengue-4 } \\
\hline & MI+ & PCR+ & MIt+ & PCR+ & MIt+ & PCR+ & MI+ & PCR+ & MI+ & PCR+ \\
\hline-7 to -4 & $2 / 2$ & $2 / 2$ & $2 / 2$ & $2 / 2$ & - & - & - & - & - & - \\
\hline-3 to -1 & $25 / 30$ & $24 / 30$ & $6 / 7$ & $6 / 7$ & $7 / 8$ & $6 / 8$ & $4 / 5$ & $4 / 5$ & $8 / 10$ & $8 / 10$ \\
\hline 0 & $5 / 14$ & $4 / 14$ & $2 / 5$ & $1 / 5$ & $1 / 3$ & $1 / 3$ & $2 / 2$ & $1 / 2$ & $0 / 4$ & $1 / 4$ \\
\hline 1 to 3 & $1 / 7$ & $2 / 7$ & $0 / 2$ & $0 / 2$ & $1 / 2$ & $1 / 2$ & $0 / 2$ & $1 / 2$ & $0 / 1$ & $0 / 1$ \\
\hline 4 to 8 & $0 / 17$ & $3 / 17$ & $0 / 4$ & $1 / 4$ & $0 / 5$ & $2 / 5$ & $0 / 4$ & $0 / 4$ & $0 / 4$ & $0 / 4$ \\
\hline Unknown & $2 / 3$ & $3 / 3$ & - & - & - & - & $2 / 3$ & $3 / 3$ & - & - \\
\hline Total & $35 / 73$ & $38 / 73$ & $10 / 20$ & $10 / 20$ & $9 / 18$ & $10 / 18$ & $8 / 16$ & $9 / 16$ & $8 / 19$ & $9 / 19$ \\
\hline
\end{tabular}

t Relative to day of defervescence.

virus detection and typing could be done in a single reaction tube. We tried this procedure with our universal primers. We obtained good results using virus stocks, but not from specimens of serum spiked with virus. We obtained rapid results using a modified method that had been applied to dengue virus with type-specific primers by Chungue and others, ${ }^{7}$ Chan and others, ${ }^{5}$ and Seah and others. ${ }^{13}$ The universal primers we used enable us to detect all four dengue serotypes in a single reaction, thus reducing the cost and preparation time of the test.

Based on the dengue virus nucleic acid sequences that were available in the Genbank database, we designed universal primers to amplify all four serotypes in a single reaction. These results show that RT-PCR using the primers we selected can detect not only laboratory strains of dengue virus, but also dengue viruses of all four serotypes in clinical specimens with high sensitivity. These data suggest that the sequences of these primers are well conserved among clinical isolates of dengue virus.

The procedure we describe in this report can rapidly indicate whether or not an acutely febrile patient is infected with dengue virus, which is critical for patient management. In the preliminary experiment, we applied our method to plasma specimens obtained on the day of presentation to the outpatient clinic, no more than $\mathbf{7 2}$ hr after the onset of fever. Dengue virus had been isolated from these specimens by mosquito inoculation. We could detect dengue RNA in 38 of these 39 samples. The only sample that was negative by PCR but positive by mosquito inoculation was obtained on the last day of fever. In the subsequent study done on serial plasma specimens obtained from children with acute febrile illness, RT-PCR detected dengue virus in $34.2 \%$ of the samples, while mosquito inoculation detected dengue virus in 29.9\%. Compared with mosquito inoculation, the overall sensitivity of the RT-PCR is $91.4 \%$ (32 of 35 ; $95 \%$ confidence interval $[\mathrm{CI}]=82.2-100 \%$ ). For the samples obtained at the time of clinical presentation, which are the most important for clinical use, this method showed a sensitivity of $95.0 \%(19$ of $20 ; 95 \% \mathrm{CI}=85.5-100 \%)$.

All first day samples and 15 of the 17 later specimens that were positive by both RT-PCR and mosquito inoculation showed a strong, distinctive band, while the two false-positive RT-PCR specimens were seen as weak bands and were negative on repeat testing. Samples obtained later in the course of acute dengue infection that were positive by RT-PCR but negative by mosquito inoculation showed weak bands, and five of six such samples were RT-PCR negative on repeat testing. This result agrees with the observations made by Gubler and others ${ }^{27}$ and Chan and others ${ }^{5}$ that samples for either virus isolation or RT-PCR should ideally be obtained in early phase of illness. These findings may reflect a low virus titer in the plasma in the later stages of illness. Gubler and others reported the presence of dengue virus at low titer in patient serum as late as 12 days after the onset of illness using the mosquito inoculation technique. ${ }^{27}$

The RT-PCR method we used had a specificity of $95.4 \%$. It is difficult to compare this result with other published methods since none of the earlier reports on dengue RT-PCR analyzed a large number of samples from patients with suspected dengue virus infection with complete serologic tests as negative controls. A possibility that cannot be overlooked is carry-over contamination; however, we exercised precautions to prevent carry-over contamination, such as the use of several samples without RNA as controls in each run, physical separation of pre- and post-PCR manipulations, and the use of aerosol-barrier pipettes.

Several investigators have reported single-step RT-PCR methods for detecting dengue virus ${ }^{6,9,11.13}$ by using different sources of RT and DNA polymerase. We tried several methods using RT-AMV (Promega) and Tth DNA polymerase (Promega), using rTth DNA polymerase (Perkin Elmer, Foster City, CA), and the Access RT-PCR ${ }^{\circledR}$ system (Promega) containing RT-AMV and Thermus flavus (TfI) DNA polymerase. We found the first two methods to be less sensitive than our method. Chang and others ${ }^{6}$ and Lanciotti and others $^{9}$ improved the sensitivity of their single-step RT-PCR by ELISA or nested PCR, respectively. Since our objective is to learn whether or not a patient is having dengue viremia on the same day, we chose to continue using the conventional two-step RT-PCR and staining of DNA bands in agarose gels with ethidium bromide. Recently, we found that the Access $\mathrm{RT}-\mathrm{PCR}^{\circledR}$ system gave a comparable sensitivity with our method for detecting viral RNA in serum spiked with dengue virus.

It is often difficult to clinically identify children with dengue until defervescence. This rapid diagnostic assay, although not superior to the mosquito inoculation technique in sensitivity, should be helpful in the rapid identification of patients with dengue in the outpatient setting early in the course of disease and useful in the early management of children with the disease. 
Acknowledgments: We thank Drs. Walter E. Brandt, Kenneth Eckels, Bruce L. Innis, Jack McCown, Jacob J. Schlesinger, and Margo A. Brinton for providing reference viruses; and Dr. Rebeca RicoHesse for providing Japanese encephalitis viral RNA. We also thank Drs. Suchitra Nimmannitya, Saroj Suntayakom, Narongchai Kunentrasai, Suntaree Ratanachuake, Wiboon Viramitrchai, Supaporn Kiatpolpoj, the pediatricians who carried out the clinical studies; Nonglak Ongsakorn, Sanguan Boonak, Naowyubol Nutkumhang, and Somsak Imlarp for virus isolation and identification; Panor Srisongkram, Ming Choohong, Piyanard Chuasuwan, and Chandana Limsomwong for technical assistance; as well as the Armed Forces Research Institute of Medical Sciences research nurses, technicians in blood processing, and patients who participated in this study.

Financial support: This publication was made possible by grant number POI-AI-34533 from the National Institutes of Health (NIH) and support from the U.S. Army Medical Research and Materiel Command.

Disclaimer: The contents of this paper are solely the responsibility of the authors and do not necessarily represent the official views of the NIH or the Department of Defense.

Authors' addresses: T. Mirawati Sudiro, Hiroaki Ishiko, Sharone Green, Alan L. Rothman, Jurand Janus, Ichiro Kurane, and Francis A. Ennis, Division of Infectious Diseases and Immunology, University of Massachusetts Medical Center, 55 Lake Avenue North, Worcester MA 01655. David W. Vaughn, Ananda Nisalak, and Boonyos Raengsakulrach, Department of Virology, U.S. Army Medical Component, Armed Forces Research Institute of Medical Sciences, Bangkok, Thailand. Siripen Kalayanarooj, Department of Infectious Disease, Bangkok Children's Hospital, Bangkok, Thailand.

Reprint requests: T. Mirawati Sudiro, Division of Infectious Diseases and Immunology, University of Massachusetts Medical Center, 55 Lake Avenue North, Worcester, MA 01655.

\section{REFERENCES}

1. Tesh RE, 1979. A method for the isolation and identification of dengue viruses, using mosquito cell culture. Am J Trop Med Hyg 28: 1053-1059.

2. Rosen L, Gubler D, 1974. The use of mosquitoes to detect and propagate dengue viruses. Am J Trop Med Hyg 23: 11531160.

3. Innis BL, Nisalak A, Nimmannitya $S$, Kusalerdchariya $S$, Chongswasdi V, Suntayakorn S, Puttisri P, Hoke CH, 1989. An enzyme-linked immunosorbent assay to characterize dengue infections where dengue and Japanese encephalitis co-circulate. Am J Trop Med Hyg 40: 418-427.

4. Clarke DH, Casals J, 1958. Techniques for hemagglutination and hemagglutinin-inhibitor with anthropod borne viruses. Am J Trop Med Hyg 7: 561-573.

5. Chan SY, Kautner IM, Lam SK, 1994. The influence of antibody levels in dengue diagnosis by polymerase chain reaction. $J$ Virol Methods 49: 315-322.

6. Chang GJ, Trent DW, Vorndam AV, Vergne E, Kinney RM, Mitchell CJ, 1994. An integrated target sequence and signal amplification assay, reverse transcriptase-PCR-enzyme-linked immunosorbent assay, to detect and characterize flaviviruses. J Clin Microbiol 32: 477-483.

7. Chungue E, Roche C, Lefevre MF, Barbazan P, Chanteau S, 1993. Ultra-rapid, simple, sensitive, and economical silica method for extraction of dengue viral RNA from clinical specimens and mosquitoes by reverse transcriptase-polymerase chain reaction. J Med Virol 40: 142-145.

8. Deubel V, Laille M, Hugnot JP, Chungue E, Guesdon JL, Drouet MT, Bassot S, Chevrier D, 1990. Identification of dengue sequences by genomic amplification: rapid diagnosis of dengue virus serotypes in peripheral blood. J Virol Methods 30: 41-54.
9. Lanciotti RS, Calisher CH, Gubler DJ, Chang GJ, Vorndam AV, 1992. Rapid detection and typing of dengue viruses from clinical samples by using reverse transcriptase-polymerase chain reaction. J Clin Microbiol 30: 545-551.

10. Morita K, Maemoto T, Honda S, Onishi K, Murata M, Tanaka M, Igarashi A, 1994. Rapid detection of virus genome from imported dengue fever and dengue hemorrhagic fever patients by direct polymerase chain reaction. J Med Virol 44: 54-58.

11. Morita K, Tanaka M, Igarashi A, 1991. Rapid identification of dengue virus serotypes by using polymerase chain reaction. $J$ Clin Microbiol 29: 2107-2110.

12. Pierre V, Drouet MT, Deubel V, 1994. Identification of mosquito-borne flavivirus sequences using universal primers and reverse transcription/polymerase chain reaction. Res Virol 145: 93-104.

13. Seah CLK, Chow VTK, Tan HC, Chan YC, 1995. Rapid, single-step RT-PCR typing of dengue virus using five NS3 gene primers. J Virol Methods 51: 193-200.

14. Henchal EA, Polo SL, Vorndam V, Yaemsiri C, Innis BL, Hoke $\mathrm{CH}, 1991$. Sensitivity and specificity of a universal primer set for the rapid diagnosis of dengue virus infections by polymerase chain reaction and nucleic acid hybridization. Am J Trop Med Hyg 45: 418-428.

15. Boom R, Sol CJA, Salimans MMM, Jansen CL, Wertheim-van Dillen PME, vander Noorda J, 1990. Rapid and simple method for purification of nucleic acids. J Clin Microbiol 28: 495503.

16. Fu J, Tan BH, Yap EH, Chan YC, Tan YH, 1992. Full-length cDNA sequence of dengue type 1 virus (Singapore strain S275/90). Virology 188: 953-958.

17. Putnak JR, Charles PC, Padmanabhan R, Irie $\mathrm{K}$, Hoke $\mathrm{CH}$, Burke DS, 1988. Functional and antigenic domains of the dengue-2 virus nonstructural glycoprotein NS-1. Virology 163: 93-103.

18. Deubel V, Kinney RM, Trent DW, 1988. Nucleotide sequence and deduced amino acid sequence of the nonstructural proteins of dengue type 2 virus, Jamaica genotype: comparative analysis of the full-length genome. Virology 165: 234-244.

19. Hahn YS, Galler R, Hunkapiler T, Dalrymple JM, Strauss JH, Strauss EG, 1988. Nucleotide sequence of dengue-2 RNA and comparison of the encoded proteins with those of the other flaviviruses. Virology 162: 167-180.

20. Osatomi K, Sumiyoshi H, 1990. Complete nucleotide sequence of dengue type 3 virus genome RNA. Virology 176: 643647.

21. Mackow E, Makino Y, Zhao BT, Zhang YM, Markoff L, Buckler-White A, Guiler M, Chanock R, Lai CJ, 1987. The nucleotide sequence of dengue type 4 virus: analysis of genes coding for nonstructural proteins. Virology 159: 217-228.

22. Sumiyoshi H, Mori C, Fuke I, Morita K, Kuhara S, Kondou J, Kikuchi Y, Nagarnatu H, Igarashi A, 1987. Complete nucleotide sequence of the Japanese encephalitis virus genome RNA. Virology 161: 497-510.

23. Rice CM, Lenches EM, Eddy SR, Shin SJ, Sheets RL, Strauss $\mathrm{JH}, 1985$. Nucleotide sequence of yellow fever virus: implications for flavivirus gene expression and evolution. Science 229: 726-733.

24. Coia G, Parker MD, Speight G, Byrne ME, Westaway EG, 1988. Nucleotide and complete amino acid sequences of Kunjin virus: definitive gene order and characteristics of the virusspecified proteins. J Gen Virol 69: 1-21.

25. Kontny U, Kurane I, Ennis FA, 1988. Gamma interferon augments $F c \gamma$ receptor-mediated dengue virus infection of human monocytic cells. J Virol 62: 3928-3933.

26. Kuno G, Gubler DJ, Santiago De Weil NS, 1985. Antigen capture ELISA for the identification of dengue viruses. $J$ Virol Methods 12: 93-103.

27. Gubler DJ, Suharyono W, Tan R, Abidin M, Sie A, 1981. Viraemia in patients with naturally acquired dengue infection. Bull World Health Organ 59: 623-630. 